\title{
Txr1: a transcriptional regulator of thrombospondin-1 that modulates cellular sensitivity to taxanes
}

\author{
Chih-Jian Lih, ${ }^{1}$ Wensheng Wei, ${ }^{1}$ and Stanley N. Cohen ${ }^{1,2,3}$ \\ ${ }^{1}$ Department of Genetics, Stanford University School of Medicine, Stanford University, Stanford, California 94305, USA; \\ ${ }^{2}$ Department of Medicine, Stanford University School of Medicine, Stanford University, Stanford, California 94305, USA
}

\begin{abstract}
Using transcripts initiated at a chromosomally integrated retrovirus-based promoter to perturb gene expression randomly in human prostate cancer cells, we isolated cell clones resistant to taxane lethality and discovered the role of a previously uncharacterized gene, $t \times r 1$, in this phenotype. We show that $t \times r 1$ impedes taxane-induced apoptosis in tumor cells by transcriptionally down-regulating the production of thrombospondin-1 (TSP-1) — known earlier for both its anti-angiogenic and proapoptotic actions. Decrease of Txr1 or treatment with TSP-1 or TSP-1 mimetic peptide sensitized cells to taxane cytotoxicity by activating signaling through the CD47 receptor (also known as the integrin-associated protein), whereas interference with CD47 function reduced taxane-induced cell death. Cellular abundance of Txr1 and TSP-1 varied inversely, and alteration of the level of both proteins correlated highly with taxol resistance in 13 of 19 NCI-60 cancer cell lines. Our results reveal a hitherto unsuspected mechanism of taxane resistance, elucidate the role of $\operatorname{txr} 1$ in this resistance, and identify txr1 as a regulator of TSP-1 production and an agent for its chemotherapeutic modulation.
\end{abstract}

[Keywords: Thrombospondin-1; CD47; taxanes; microarray; angiogenesis; Txr1]

Supplemental material is available at http://www.genesdev.org.

Received April 17, 2006; revised version accepted June 5, 2006.

Taxanes are a family of major chemotherapeutic agents that have anti-neoplastic effects against a wide spectrum of human cancers (Rowinsky 1997). The anti-proliferative actions of the two clinically employed taxanes, paclitaxel (taxol) and docetaxel, stem from their ability to interact with $\beta$-tubulin and promote tubulin polymerization and stability; this event blocks cell cycling at the $\mathrm{G}_{2}-\mathrm{M}$ transition and results in eventual cell death by apoptosis (Horwitz 1992). Despite a dramatic response of susceptible tumors to initial treatment with taxanes, the subsequent development of resistance has proved to be a major limitation to long-term use of these agents as anticancer drugs (Horwitz et al. 1993). A widely studied mechanism associated with such resistance is the exclusion of taxanes and other drugs from cells by up-regulation of ATP-dependent cell membrane P-glycoproteins (i.e., transporter-related multidrug resistance [MDR]) (Bradley and Ling 1994). Genetic mutations that interfere with the binding of taxanes to microtubules have also been extensively investigated as a cause of taxol

${ }^{3}$ Corresponding author.

E-MAIL sncohen@stanford.edu; FAX (650) 725-1536.

Article published online ahead of print. Article and publication date are online at http://www.genesdev.org/cgi/doi/10.1101/gad.1441306. resistance (Giannakakou et al. 1997; Kavallaris et al. 1997; Ranganathan et al. 1998; Monzo et al. 1999).

In recent years, several approaches that use functionbased screens for the discovery of cellular genes whose inactivation or overexpression yields phenotypic properties of interest have been developed (Li and Cohen 1996; Kimchi 2003; Primiano et al. 2003; Berns et al. 2004; Lu et al. 2004). One of these (Li and Cohen 1996) uses an experimentally regulated chromosomally integrated virus-based promoter to modulate the expression of genes at the site of viral insertion. Using this approach, we identified a previously unknown gene, txr1, which encodes an 18-kDa proline- and serine-rich nuclear protein and whose altered expression confers resistance to taxol. We show that $t \times r 1$ transcriptionally down-regulates expression of the anti-angiogenic and proapoptotic glycoprotein thrombospondin-1 (TSP-1), that this event impedes taxane-induced apoptosis in human cancer cells, and that the cytotoxicity of taxanes is increased in cancer cells by either inactivation of Txr1 or activation of CD47 (also known as integrin-associated protein [IAP]) by TSP-1 or a TSP-1 peptide mimetic. Our findings reveal txr1 as a regulator of thrombospondin-1-mediated cell functions and suggest a potential approach for the therapeutic modulation of these functions as well as the potentiation of taxol effects. 


\section{Results}

\section{Isolation of taxol-resistant clones}

Identification of cells acquiring resistance to taxol used the overall experimental approach described by $\mathrm{Li}$ and Cohen (1996) with two major modifications in the gene search vector (GSV2) (Fig. 1A)-substitution of neo for $\beta$-geo as reporter to reduce the size of vector and consequently to increase virus production, and use of a tetracycline $(\mathrm{Tc})$ regulated promoter (TcRP) to produce antisense transcripts that inhibit the expression of chromosomal genes. M2182, a tumorigenic but nonmetastatic human prostate cancer cell line that has a relatively normal diploid karotype and that was found in initial experiments to be highly susceptible to infection by the retroviral GSV2 construct and sensitive to taxane-induced lethality, was transfected with the Tc-off transactivator gene (tTA), and a resulting clone, M2182tTA, was targeted for infection by the GSV2. A pool of M2182tTA cells containing $\sim 5 \times 10^{5}$ independent chromosomal insertions of GSV2 was exposed to $10 \mathrm{nM}$ taxol for two sequential 2-wk cycles of screening. Three clones /clones 4,14 , and 18) that formed prominent colonies at this taxol concentration were characterized further by MTT assay; clone 18, which in the absence of exposure to chemotherapeutic agents had a growth rate, cell cycle distribution, and morphology similar to that of parental M2182tTA cells but had an $\mathrm{IC}_{50}$ for taxol that was $\sim 2.5$ fold greater, was chosen for further study. Clones 4 and 14 showed a lesser increase in $\mathrm{IC}_{50}$ and produced smaller colonies when cultured in $10 \mathrm{nM}$ taxol (Fig. 1B). Addition of $1 \mu \mathrm{g} / \mathrm{mL}$ Tc to cultures of clone 18 reversed its ability to grow in the presence of either $10 \mathrm{nM}$ taxol or 2 nM docetaxel, a more potent taxane (Fig. 1C). These findings, together with the absence of detectable effects of Tc on the size or density of colonies in the culture lacking taxane, suggested that taxol resistance in clone 18 was being regulated by the TcRP promoter.
A.

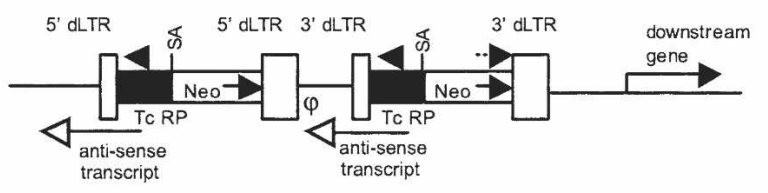

B.

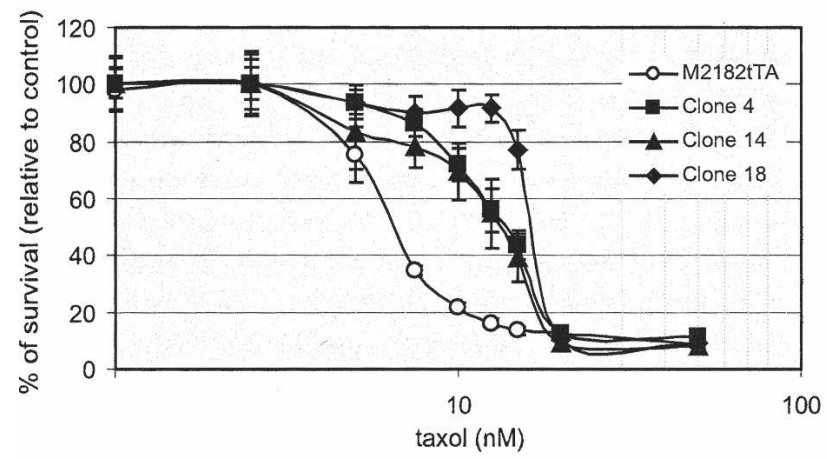

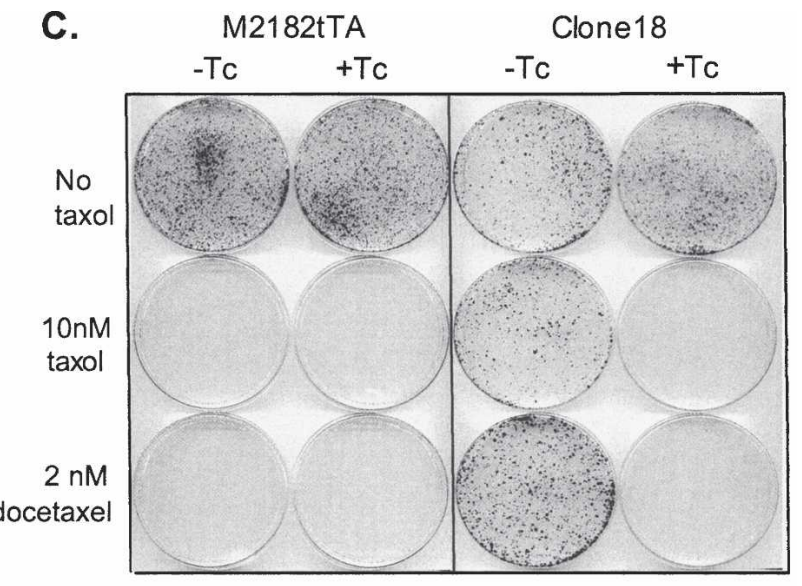

D.

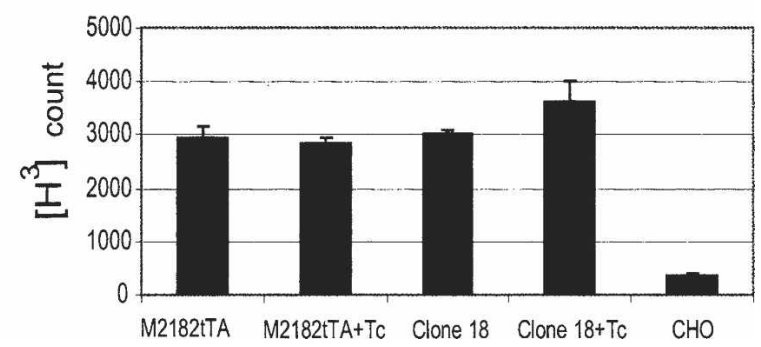

Figure 1. Identification and characterization of taxol-resistant cell clones. $(A)$ Structure of integrated provirus derived from retroviral gene search vector (GSV2). 3'dLTR or 5'dLTR (open boxes) designate defective retroviral long terminal repeats lacking promoter and enhancer sequences required for virion production; (SA) splicing acceptor site from adenovirus; (neo) reporter gene encodes resistance to G418 (arrow in box indicates the "sense" direction of transcription; broken arrow at the top indicates the location and 5'-to-3' direction of the primer used for cloning genes adjacent to the integration site); (TcRP [filled box]), tetracycline regulated promoter (arrowhead above this box indicates the direction of transcription; lines with open arrowhead below this box indicate anti-sense transcript originating from TcRP); $(\varphi)$ virus packaging signal. (B) Survival of cell clones resistant to taxol as determined by MTT assay. The percentage of surviving cells ( $Y$-axis) at the indicated taxol concentrations (in nanomolar [nM]; $X$-axis) was calculated from MTT assay readouts relative to the untreated control (set as 100\%). Each data point represents the mean \pm SD from eight replicates. $(C)$ Tc modulation of taxane resistance in clone 18. Cellular sensitivity to taxanes was analyzed by plate assays in the presence $(+\mathrm{Tc})$ or absence $(-\mathrm{Tc})$ of tetracycline $(1 \mathrm{\mu g} / \mathrm{mL})$ as described in Materials and Methods. $(D)$ Taxol uptake in clone 18. Cell lines were incubated with $\left[{ }^{3} \mathrm{H}\right]$ taxol in the presence or absence of Tc, and uptake was determined by scintillation counting. Chinese hamster ovary (CHO) cells with high efflux activity (Parekh and Simpkins 1996) were used as control. Each histogram represents the mean \pm SD of four independent experiments. 
Lih et al.

Altered functioning of ATP-binding cassette P-glycoproteins and consequent effects on the efflux of taxol and other chemotherapeutic agents is a well-documented mechanism of resistance to taxanes (Bradley and Ling 1994). However, we found no evidence of reduced killing of clone 18 cells by the DNA-damaging agents adriamycin and etoposide, by the microtubule-destabilizing agents vincristine and vinblastine, or by the microtubule-stabilizing drug epothilone B, suggesting that their taxol resistance is not the result of MDR (Supplemental Table S1). Consistent with this conclusion was evidence that $2 \mu \mathrm{M}$ cyclosporin $\mathrm{A}$, which has been reported to reverse the cellular effects of MDR (Xu et al. 2001), did not affect the taxol resistance (data not shown). Moreover, whereas down-regulation of the TcRP promoter in the chromosomally inserted GSV2 of clone 18 cells decreased taxol resistance (Fig. 1C), it did not alter the intracellular accumulation of $\left[{ }^{3} \mathrm{H}\right]$-labeled taxol (Fig. 1D). Clone 18 cells also showed normal expression of $\beta$-tubulin class I and III microtubule proteins, which commonly are elevated in taxol resistance secondary to altered microtubule function (Supplemental Fig. S1A; Kavallaris et al. 1997). Furthermore, the relative amount of solubilized and polymerized forms of tubulin were similar in taxol-treated clone 18 cells and parental M2182tTA cells (Supplemental Fig. S1B). Collectively, these results argue strongly that taxol resistance in clone 18 resulted from a mechanism different from the two previously studied ones (i.e., MDR and microtubule alteration).

\section{Identification and characterization of Txr1}

Southern blot analysis indicated that the proviral form of the GSV2 had integrated at a single chromosomal site in clone 18 cells (data not shown). Genomic DNA fragments flanking this site were cloned using a PCR-based genome walking method (Materials and Methods), and analysis of their sequences by the BLAT program (http:// genome.ucsc.edu) showed that insertion of GSV2 had occurred at a locus on Chromosome 12 (region 12q13.13) $499 \mathrm{bp} 5^{\prime}$ to a putative gene sequence identified from expressed sequence tags (GeneID 54458; symbol DKFZp564J157). The longest of these ESTs (accession number BC001464) is 1189 bp in length and consists of four proposed exons that on the chromosome extend over a distance of $5 \mathrm{~kb}$ (Fig. 2A). We designated the locus as txr1 (taxol resistance gene 1). ESTs corresponding to txr1 exist in at least three transcriptional variant forms: variant 1 (NM_001005355), variant 2 (NM_018457), and variant 3 (NM_001005354). Variants 1 and 2 both contain a deletion in the $5^{\prime}$-UTR and encode an open reading frame (NP_001005355) whose sequence corresponds to a 148-amino acid protein of 15,243 Da (Fig. 2B). Part of the $5^{\prime}$-UTR and ORF is deleted in variant 3 , which encodes an isoform (NP_001005354) lacking the coding sequence for the first 56 amino acids.

The amino acid composition of the predicted Txr1 proteins is noteworthy. The longest predicted protein (Txr1) contains 44 proline residues (29.7\% of the entire protein) in the first 101 amino acids, eight histidines and 13 lysines in the C-terminal 48-amino-acid segment, and remarkably, a continuous stretch of 10 serine residues at the $\mathrm{C}$ terminus (Fig. 2B). Further analysis revealed several putative $\alpha$-helix motifs in the first 100 amino acids of the protein and putative $\beta$-sheet structures near the C-terminal end. While the prolines in Txr1 could be aligned spatially with prolines in other proteins having biological functions that include $\mathrm{SH} 3 / \mathrm{WW}$ domain binding, RNA binding, and cell mobility, no detectable homology with other proteins in interproline stretches was observed.

Northern blot analysis of total RNA isolated from clone 18 detected a single txr 1 transcript species migrating in agarose gels at $1.2 \mathrm{~kb}$, which corresponds in length to expression sequence tag (EST) variant 1 . This transcript species was up-regulated fivefold in clone 18-and in the presence of Tc was reduced to the level found in the parental cell line (Fig. 2C, upper panel). Increased txr1 transcription in clone 18 was confirmed by RT-PCR analysis (Fig. 2C, lower panel). Consistent with these results, immunoblotting experiments showed that the abundance of an $18-\mathrm{kDa}$ species corresponding in size to the predicted full-length Txrl protein was fivefold higher in clone 18 than in parental cells and that its up-regulation was reversed by Tc (Fig. 2D). Immunofluorescence staining using anti-Txr1 antibody showed that Txr1 is localized predominantly in the nucleus, as did direct visualization of a Txr1-GFP fusion protein (Fig. 2E). Multiple-tissue Northern blotting indicated that txr1 transcripts are broadly expressed and are especially prominent in the normal heart and kidney and in leukocytes (Fig. 2F).

Txr1 up-regulation is necessary for the taxane resistance of clone 18 and is sufficient to increase cellular resistance to taxanes in naive cells

We further confirmed the role of Txr1 in the taxol resistance of clone 18, and-in experiments that used two small interfering RNAs (siRNA1 and 2) complementary to the $5^{\prime}$ - and $3^{\prime}$-untranslated regions of $\operatorname{txr} 1$ to reduce expression of the gene-showed that up-regulation of Txr1 is necessary for this resistance. Clone 18 cells that were transiently transfected with siRNAs against txr1 showed a $75 \%-80 \%$ decrease in cell survival in the presence of $10 \mathrm{nM}$ taxol (Fig. 3A-C) and a concomitant reduction in steady-state level of Txr1 protein as assessed by immunoblotting (Fig. 3D). Similarly, treatment of naive M2182tTA cells with siRNAs directed against txr1 resulted in decreased survival in the presence of taxol (Fig. 3E-H) but no difference in sensitivity to the nontaxane chemotherapeutic drugs adriamycin, etoposide, vinblastine, vincristine, and epothilone B /data not shown). In experiments aimed at reconstituting the taxol-resistance phenotype in naive cells, we were unable to isolate clones that stably expressed Txr1 from the CMV promoter. However, infection of M2182tTA cells with the lentiviral construct pLEST-Txr1HA, which 
A.

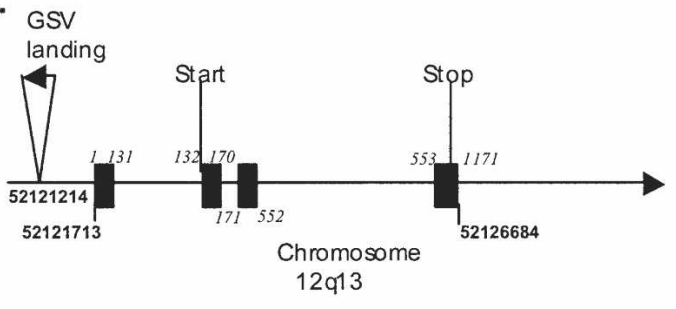

B.

MWNPNAGOPG PNP YPPNIGCPGGSN PAH PDP INP PFP PGPCPP PPGAPHG

NPAF PPGGPPHPV PQPGYPGCQ PLG PYP PPY PPPAPG IPPVNP LAP GMV

PAVI VDKKMQKKMMKKAHKKMHKHQKHHKYHKHGKHSS SSS SSS SSDSD

C.

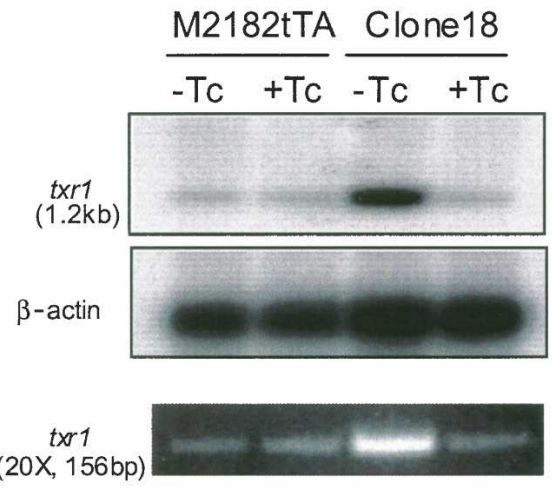

D.

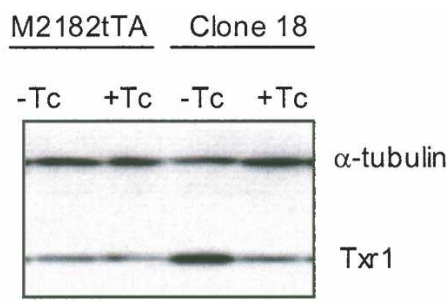

E.

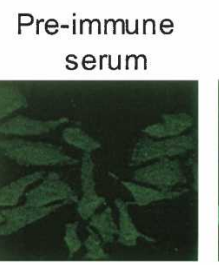

GFP alone

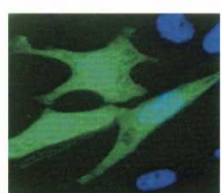

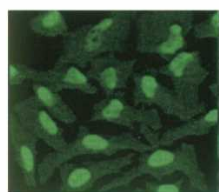

anti-Txr1

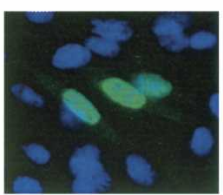

Tx1-GFP
F.

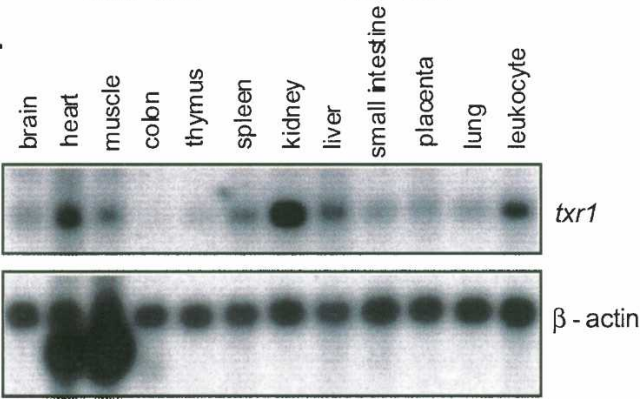

Figure 2. Cloning, expression, and localization of $\operatorname{txr} 1$. (A) Schematic diagram of the GSV2 integration site in clone 18 and txr1 gene structure. Integration site of GSV2 provirus (inverse triangle; arrowhead indicates the direction of transcription from the Tc-regulated promoter) is shown at Chromosome locus 12q13 (horizontal line). The genomic nucleotide coordinates for the integration site and for the start and the end of txr1 transcripts are indicated in bold type. Four exons of the txr1 gene are shown as solid boxes, and their coordinates are italicized. The codons initiating and terminating translation (start and stop, respectively) are indicated. (B) Txr1 protein sequence deduced from cDNA sequence. The peptide used as antigen for raising antibodies is underlined. $(C)$ Tc modulation of $t \times r 1$ transcript in clone 18. txr1 transcript abundance in the presence or absence of Tc was analyzed by Northern blotting (top panels). The same RNAs were used as template for RT-PCR analysis (bottom panel). The cycle number and product size of the product are indicated. $(D)$ Tc modulation of Txr1 protein in clone 18. Txr1 protein abundance in the presence or absence of Tc was measured by immunoblotting analysis. (E) Intracellular localization of Txr1. HeLa cells were immunofluorescence-stained with preimmune serum (upper left) or anti-Txr1 polyclonal antibodies (lower left). Chinese hamster ovary cells transfected with pCMV-EGFPN1 (upper right) or pEGFPTxr1 (lower right) were stained with DAPI (blue). Fluorescent images were obtained by confocal microscopy. $(F)$ Multiple tissue Northern blot.

uses the TcRP promoter to express Txr1 protein tagged with hemagglutinin (HA), and selection for continued cell growth in the presence of Tc led to the isolation of two clones (R1 and R2) that stably express Txr1. In the absence of Tc, these clones showed induced expression (threefold in R1 and 2.5-fold in R2) (Fig. 4A) of HA-tagged Txr1, which migrated more slowly than endogenous Txr1 in SDS-PAGE, and also showed increased survival in the presence of taxol concentrations of 2.5-4 nM (Fig. 4B-E)-confirming the role of txr1 in taxol resistance. The different level of taxol resistance in reconstituted clones versus clone 18 may reflect differences in Txr1 expression expected to result from integration of the lentivirus construct at different chromosomal sites.

\section{Txr1 effect on taxane cytotoxicity is mediated through TSP-1}

In initial experiments aimed at elucidating the mechanism underlying the taxane resistance observed in cells overexpressing Txr1, we used cDNA microarrays to compare gene expression profiles for clone 18 and M2182tTA cells in the presence or absence of Tc. The resulting data, which we analyzed using the GABRIEL rule-based computer programs (Pan et al. 2002), identified 59 up-regulated genes (FDR $<0.001)$ and 49 downregulated ones $(\mathrm{FDR}=0.001)$ (Fig. $5 \mathrm{~A}$; see gene list in Supplemental Table S2). Txr1 itself was the most upregulated gene $(6.8 \pm 1.0-$ fold $)$, consistent with the 
Lih et al.

Clone 18

A.

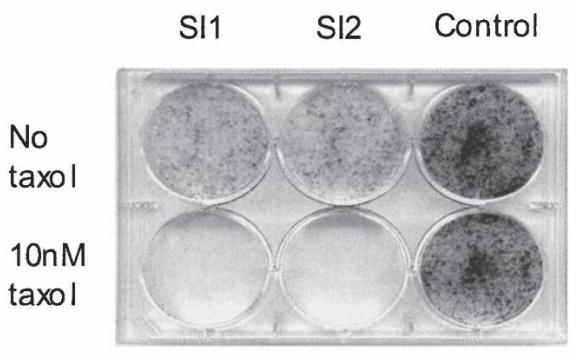

B.

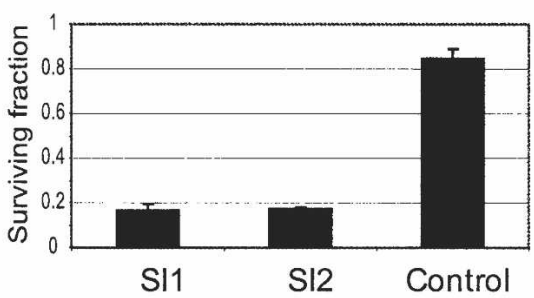

c.

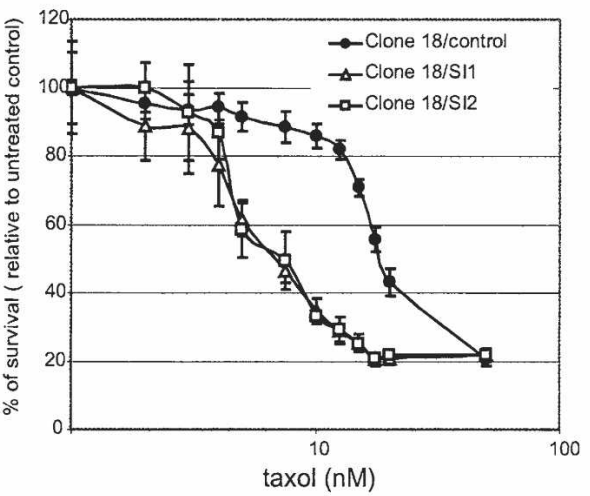

D.

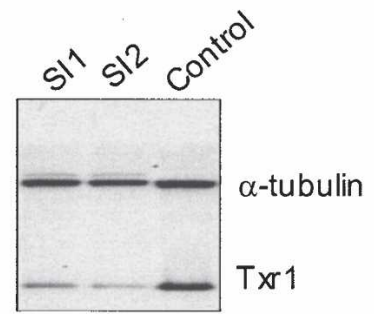

M2182tTA

E.

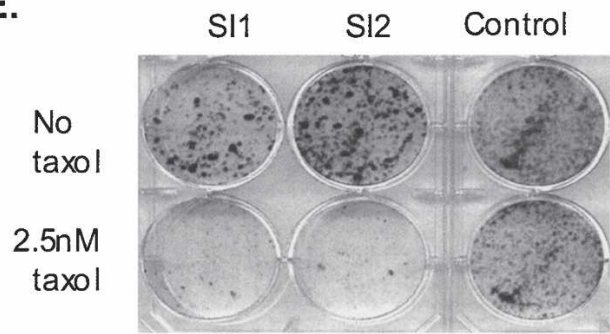

F.

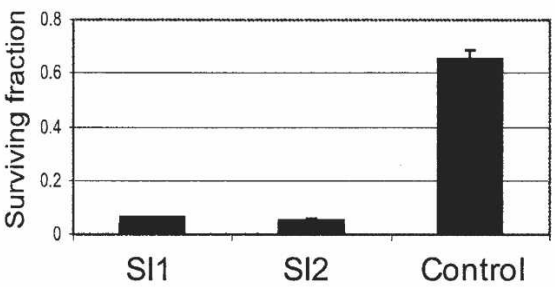

G.

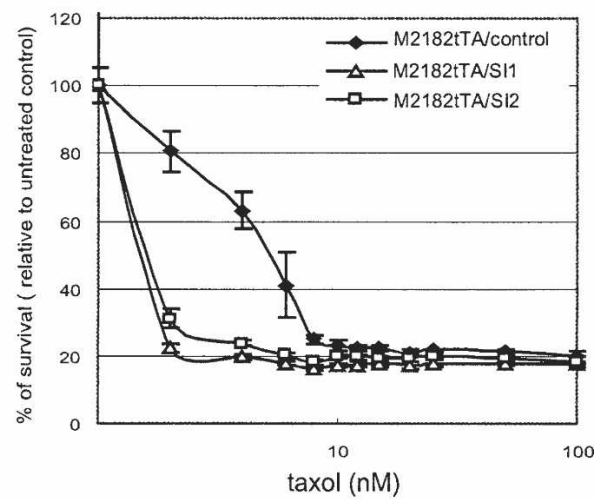

H.

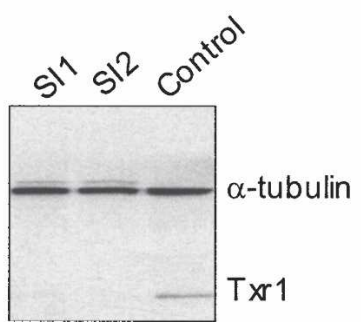

Figure 3. Down-regulation of txr1 by siRNA reduces the taxol resistance of clone $18(A-D)$ and increases taxol sensitivity of naive M2182tTA cells $(E-H)$. $(A, E)$ Effect of Txr1 deficiency on taxol resistance. Clone $18(A)$ and M2182tTA cells $(E)$ were transfected with siRNA (SI1 and SI2) against txr1 and with a scrambled-sequence control and then seeded for plate assay in the presence of $10 \mathrm{nM}$ taxol (for clone 18) and $2.5 \mathrm{nM}$ taxol (for M2182tTA). (B,F) Quantitative measurement of surviving cell fraction. Crystal violet-stained surviving cells in $A$ and $E$ were incubated with DMSO, and the absorbance was measured as indicated in Materials and Methods. The fraction of surviving cells was determined by normalizing the readouts from taxol-treated cells $(A, E$, lower row) to untreated controls $(A, E$, upper row). Results are means \pm SD of two independent experiments. $(C, G)$ Effect of anti-Txr1 siRNA on cell survival. Cells transfected with siRNA were analyzed by MTT assay as indicated in Materials and Methods. Each data point represents the mean \pm SD from four replicates. $(D, H)$ Immunoblotting analysis effects of siRNA on Txrl protein abundance. Cell lysates of siRNA transfected cells were subjected to immunoblotting analysis.

prominently increased mRNA abundance we had detected by Northern blotting and RT-PCR (Fig. 2C). The most down-regulated transcript (3.65 \pm 0.8 -fold) among the $\sim 28,000$ unique genes analyzed on microarrays (Fig.
5A, lower panel) was thrombospondin-1 (TSP-1), which previously had been studied extensively for its ability to interfere with angiogenesis by inducing apoptosis of endothelial cells (de Fraipont et al. 2001; Sargiannidou et al. 
A.

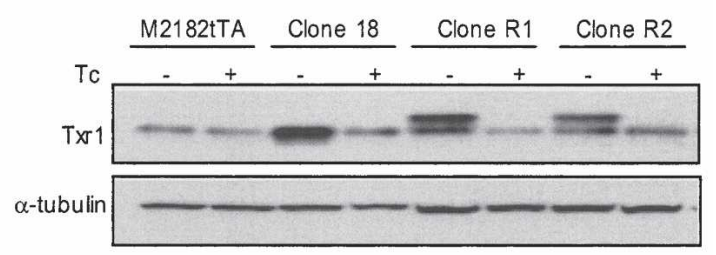

B.

C.

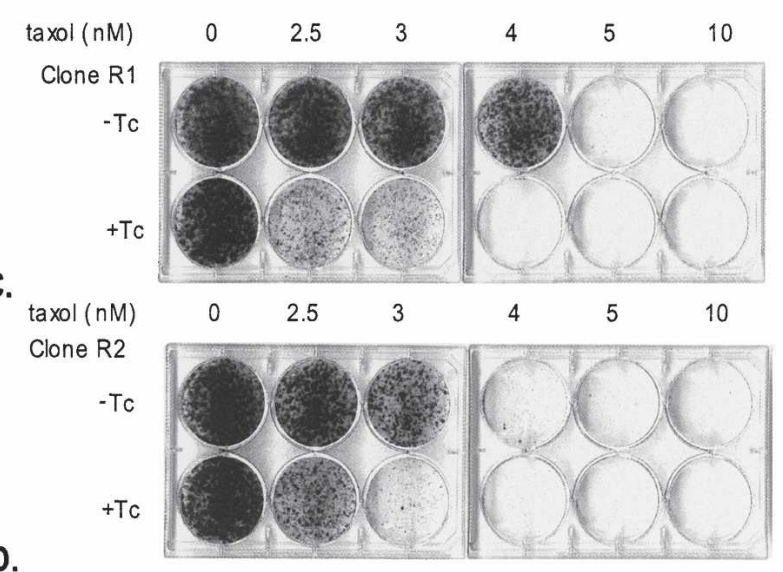

D.

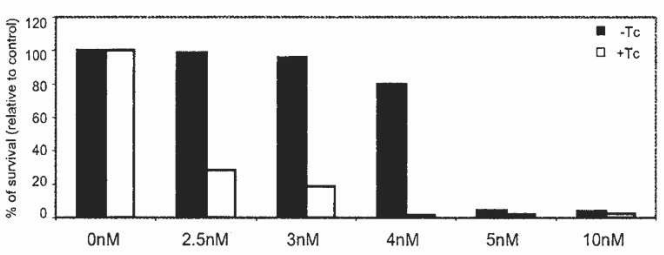

E.

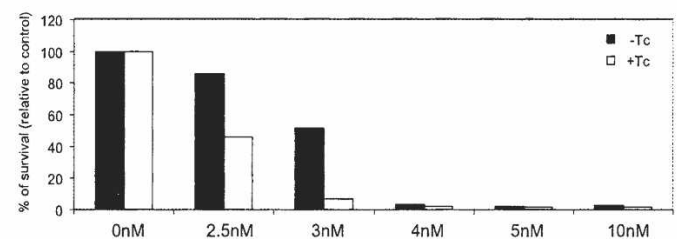

Figure 4. Up-regulation of Txr1 increases taxol resistance in naive cells. (A) Immunoblotting analysis. M2182tTA was infected with virus derived from pLESTTxr1HA, and two permanently expressing clones R1 $(B)$ and R2 $(C)$ were isolated. Cell lysates of cells in the presence or absence of $1 \mu \mathrm{g} / \mathrm{mL}$ Tc were subjected to immunoblotting analysis. $(B, C)$ Effect of Txr1 overexpression on taxol resistance in naive cells. Cells of clones R1 $(B)$ and $\mathrm{R} 2(C)$ were then seeded for plate assay at indicated taxol concentrations in the presence or absence of $1 \mu \mathrm{g} / \mathrm{mL}$ Tc. $(D, E)$ Quantitative measurement of surviving fraction of clones R1 $(D)$ and R2 $(E)$. Crystal violet-stained surviving cells in $B$ and $C$ were incubated with DMSO, and the absorbance was measured as indicated in Materials and Methods. The fraction of surviving cells was determined by normalizing the readouts from taxoltreated cells to untreated controls (leftmost column in $B$ and $C$ ).

2001; Volpert and Alani 2003). Recent evidence indicates that TSP-1 can also promote apoptosis of leukemia blood cells (Li et al. 2003). Analysis of gene expression data using the proband-based rule of GABRIEL showed a dramatically negative Pearson correlation coefficient $(r=-0.92)$ between $\operatorname{txr} 1$ and TSP-1. Northern blotting confirmed that TSP-1 RNA abundance was sharply decreased in clone 18 when Tc, which represses expression of Txr1 in this clone, was absent from the media and that expression of TSP-1 in the parental cell line was unaffected by Tc (Fig. 5B).

While altered TSP-1 expression previously has not been reported to affect taxane cytotoxicity, we noticed that certain genes that modulate taxol effects (e.g., p53 and Id1) (Wahl et al. 1996; Cheung et al. 2004) are among those identified in separate experiments as regulators of TSP-1 abundance (Volpert et al. 2002a; Harada et al. 2003). Interestingly, TSP-1 also has been observed recently to be elevated during taxane treatment of cancers (Yoo et al. 2002, 2005; Damber et al. 2006), leading to the suggestion that its anti-angiogenic effects may enhance the lethality of taxol therapy. To investigate further a possible functional relationship between expression of Txr1, expression of TSP-1, and taxane cytotoxicity in cancer cells, we analyzed a previously published data set for gene expression in NCI-60 cancer cell lines (Scherf et al. 2000). We found that that the abundance of Txr1 and TSP-1 mRNA varied reciprocally $(r=-0.83)$ in 13 of 19 cell lines in which suitable expression data were available for both genes. In these 13 lines, taxol cytotoxicity showed both a prominent negative correlation with the steady-state level of expression of $\operatorname{txr} 1(r=-0.86)$ and a positive correlation with TSP-1 $(r=0.67)$ (Fig. 5C). Immunoblot analysis in four of the 13 lines showed that inverse expression between Txrl and TSP-1 exists also at the protein level (Fig. 5D). Our results indicate that reciprocal expression of Txr1 and TSP-1 occurs commonly among cancer cell lines and, furthermore, that the extent of expression of these two genes in multiple cancer cell types is correlated with the extent of cellular sensitivity to taxol.

The mechanism for the observed down-regulation of TSP-1 mRNA abundance by Txrl was determined by using firefly luciferase cDNA fused to the TSP-1 promoter region as a reporter to specifically monitor TSP-1 transcription (Fig. 5E). In a Tc-regulated, Txr1-expressing, M2182-derived clone (i.e., R2) (Fig. 4) and in a HeLa cellderived clone in which we adventitiously expressed Txr1 under the control of the TcRP promoter, addition of Tc resulted in a five- to sixfold increase in abundance of the endogenous TSP-1 protein (Fig. 5E, upper panel), accompanied by a similar increase in luciferase activity encoded by the TSP-1/luc fusion construct (Fig. 5E, lower panel). These results established directly that Txr1 negatively regulates TSP-1 expression at the level of transcription.

\section{Effect of TSP-1 protein on taxane-mediated cytotoxicity and apoptosis}

As TSP-1 normally is secreted and exists as an extracellular protein (Sid et al. 2004), we were able to investigate TSP-1 effects on the cytoxicity of taxane and other chemotherapeutic agents in clone 18 cells by adding purified TSP-1 protein to cells growing in culture. Whereas such TSP-1 treatment resulted in dose-dependent partial reversal of taxol resistance (Fig. 6A), no effect of TSP-1 on 
Lih et al.

A.
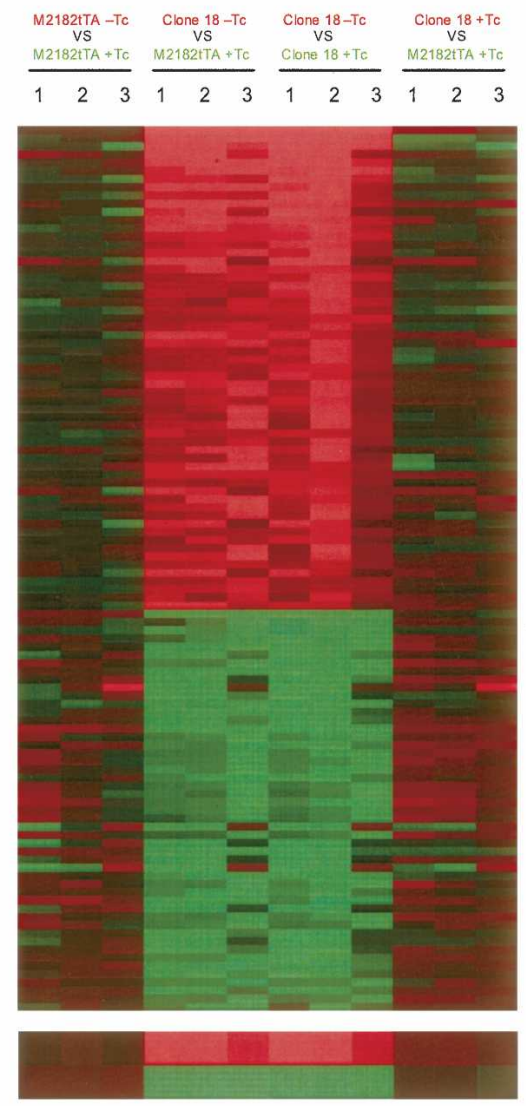

txr1

TSP-1

B.

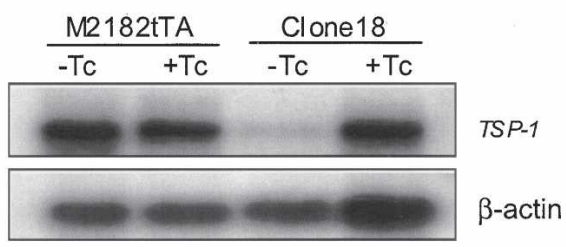

c.

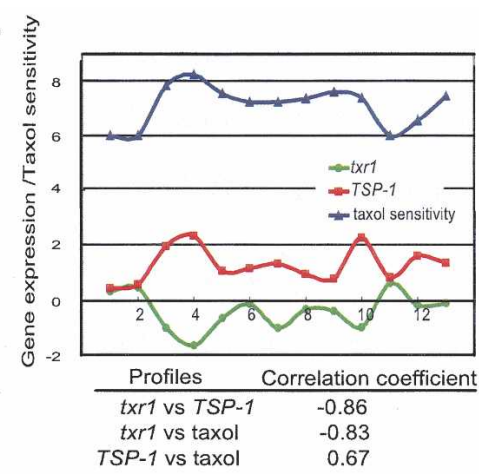

D.

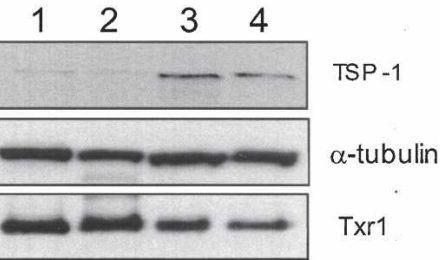

E.
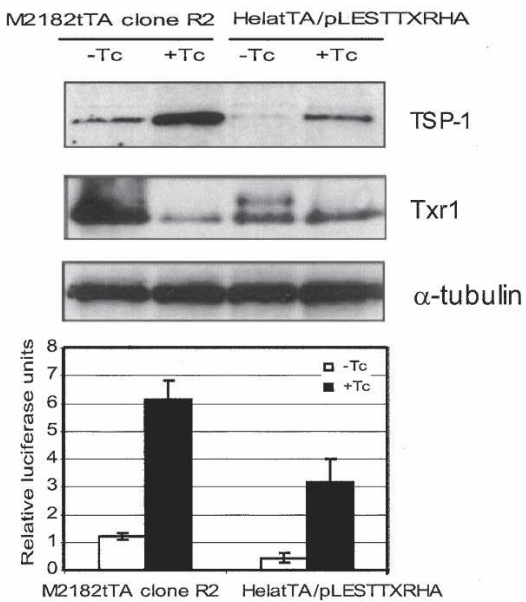

Figure 5. Effect of Txr1 on transcription of TSP-1. (A) Graphic representation of global effects of Txr1 up-regulation on transcription as measured by cDNA microarray hybridization. cDNAs corresponding to mRNA extracted from indicated cells/conditions were labeled with Cy5 (typed in red) or Cy3 (typed in green) and mixed for competitive hybridization on microarrays. Three independent hybridizations were performed for each paired comparison. Color represents the direction of regulation in gene expression: green, decreased expression; red, increased expression; black, unchanged. Color saturation is proportional to the magnitude of the change in relative expression. The gene list is provided in Supplemental Table S2. Expression profiles for Txr1 and TSP-1 are displayed in the lower panel. (B) Northern blot analysis confirms the reciprocal gene expression of Txr1 and TSP1. (C) Correlations between expression profiles of txr1 (green squares) and TSP-1 (red circles) and with cellular sensitivity to taxol (blue triangles) in tumor cell lines. Data for gene expression and taxol sensitivity were extracted and analyzed as described in Materials and Methods. The $Y$-axis represents either expression data (green and red curves) that have been transformed into the base 2 logarithm, or taxol sensitivity (blue curve) that was represented as the negative base 10 logarithm of GI50 (-log GI50; drug concentration caused 50\% of growth inhibition in molar units). The $X$-axis indicates each of 13 cancer cell lines, which are (1) OVCAR-4 (ovarian cancer), (2) ADR-RES (unknown), (3) HS_578T (breast cancer), (4) SNB-75 (central nerve system tumor cell line), (5) SF-268 (glioblastoma), (6) SK-MEL-2 (melanoma), (7) MDA-MB-231 (breast cancer), (8) RXF-393 (renal carcinoma), (9) U251 (glioblastoma), (10) SK-OV-3 (ovarian cancer), (11) UO-31 (renal carcinoma), (12) EKVX (non-small-cell lung cancer), and (13) BT-549 (breast cancer). Pearson correlation coefficients between profiles of gene expression or profiles of gene expression and taxol sensitivity are shown. $(D)$ Immunoblotting analysis of expression of TSP-1 and Txr1 proteins in NCI-60 cell lines. Lanes 1-4 represent cell lines 1-4 in C (OVCAR4, ADR_RES, HS578T, SNB-75). (E) Luciferase assay for TSP-1 promoter activity. pTSP1.7Luc was introduced by transfection, and cells were cultured in the presence or absence of Tc. Protein abundance (upper panel) of Txr1 and TSP-1 and luciferase activity were measured $2 \mathrm{~d}$ later. Relative luciferase units were calculated by normalizing luciferase activity with $\beta$-gal activity (lower panel) in cotransfected cells. Results represent the mean \pm SD from three independent measurements. 
A.

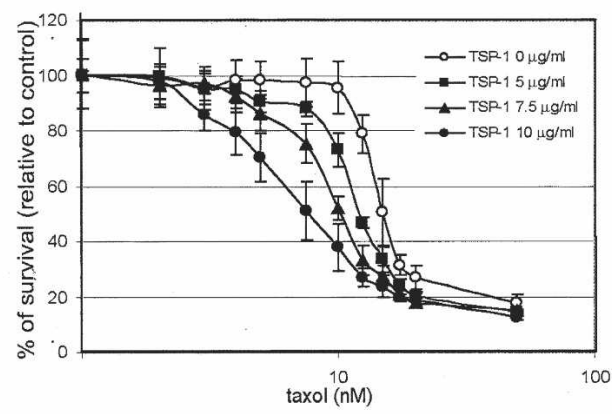

C.
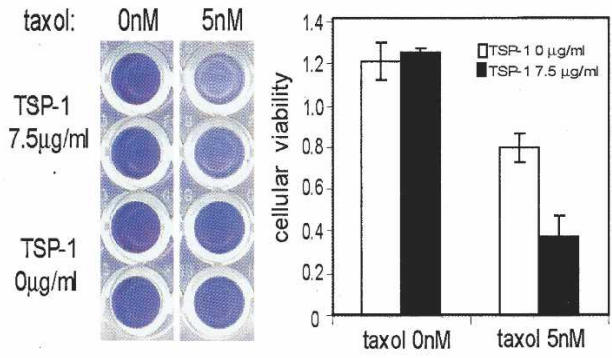

E.

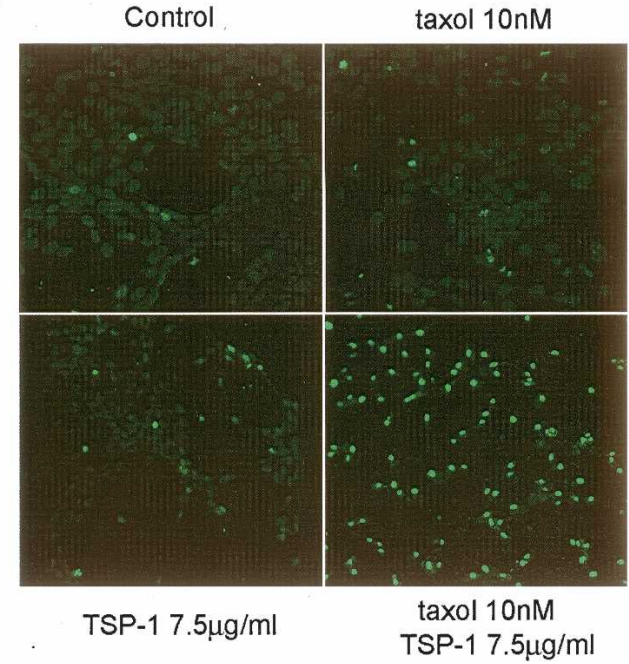

B.

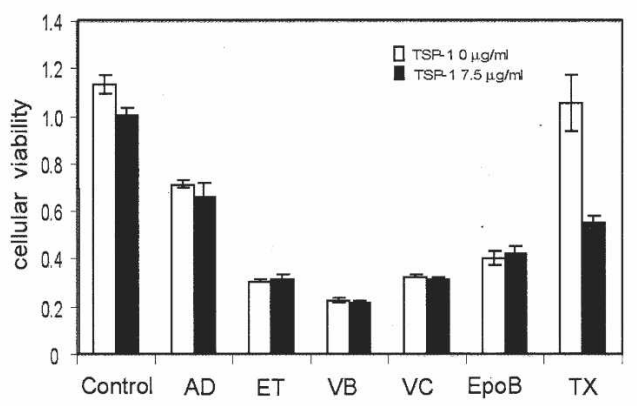

D.

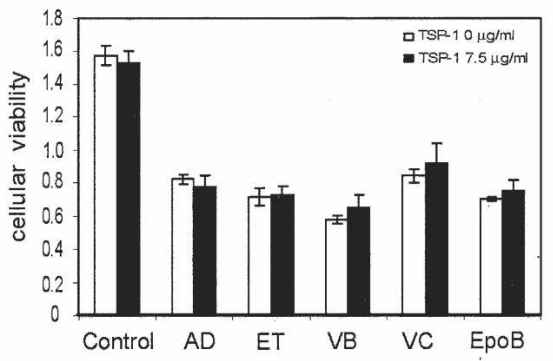

F.

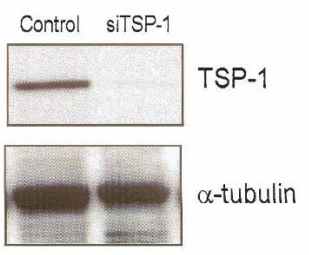

G.

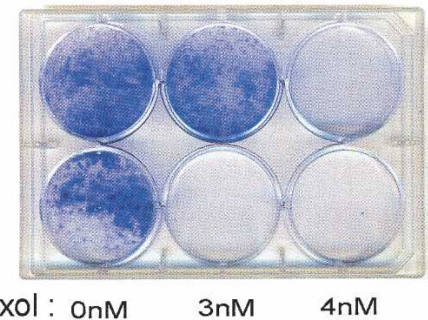

siTSP-1

Control

Figure 6. TSP-1 effect on taxol resistance. $(A)$ Dosage-dependent reversal of taxol resistance in clone 18 by TSP-1. Viability of clone 18 cells treated with the indicated concentrations of TSP-1 was assessed by MTT assay at various concentrations of taxol. Each data point represents the mean \pm SD from four replicates. $(B)$ The drug-sensitizing effect of TSP-1 is specific to taxol. Viability of clone 18 cells treated with indicated anti-cancer drugs in the presence or absence of TSP-1 was assessed by MTT assay. Histograms represent the mean \pm SD of four independent repeat experiments. (AD) $250 \mathrm{ng} / \mathrm{mL}$ adriamycin, (ET) $1 \mu \mathrm{M}$ etoposide, (VB) $10 \mathrm{nM}$ vinblastine, (VC) $10 \mathrm{nM}$ vincristine, (EpoB) $7.5 \mathrm{nM}$ epothilone B, and (TX) $10 \mathrm{nM}$ taxol. (C) TSP-1 effects on taxol sensitivity of naive cells. Viability of M2182tTA cells treated with taxol or TSP-1 alone, or with both, as indicated, was assessed by MTT assay. Images of wells after MTT color reaction are displayed in the left panel. Histograms represent the mean \pm SD of four independent repeats. $(D)$ The drug-sensitizing effect of TSP-1 is specific to taxol in naive cells. (E) TSP-1 enhances cellular sensitivity to taxol by triggering apoptotic cell death. Apoptotic cells of clone 18 cells treated with taxol or TSP-1 alone, or both, as indicated, were assessed by TUNEL assay and viewed by confocal microscopy. The bright green fluorescent nuclear spots represent TUNEL-positive cells. $(F)$ Immunoblotting analysis of M2182tTA cells transfected with siRNA against TSP-1. $(G)$ Effect of TSP-1 deficiency on taxol resistance in naive cells. Taxol sensitivity of M2182tTA cells transfected with siRNA against TSP-1 or a scrambled-sequence control was analyzed by plate assay. 
Lih et al.

the lethality of the other chemotherapeutic agents that we tested was observed (Fig. 6B). TSP-1 treatment alone had little or no effect on the survival of clone 18 cells at the same dosage tested in these experiments (Fig. 6B). Addition of TSP-1 to cultures of naive M2182tTA cells also reduced survival to taxol-mediated lethality but not to lethality mediated by other chemotherapeutic agents (Fig. 6C,D). Consistent with the above results, TSP-1 dramatically and synergistically increased taxol-induced apoptosis, as determined by TUNEL assay (Fig. 6E). Conversely, decreasing the expression of endogenous TSP-1 to $<10 \%$ of the control level (Fig. $6 \mathrm{~F}$ ) by treatment of naive M2182tTA cells with short interfering RNA (siRNA) directed against TSP-1 transcripts enabled cell survival at a taxol concentration $(3 \mathrm{nM})$ that was lethal to an identical cell population transfected with control siRNA having a randomly scrambled sequence (Fig. 6G). Lethality of other chemotherapeutic drugs in M2182 cells was unchanged by reduction of TSP-1 expression (data not shown).

\section{Sensitization to taxanes by TSP-1 is signaled through the CD47 cell surface receptor protein}

The results presented above indicate that Txr1 transcriptionally down-regulates expression of TSP-1, that such down-regulation reduces taxane-induced apoptosis, and that treatment of taxane-resistant prostate cancer cells with TSP-1 protein increases the cytotoxicity of taxanes without affecting the actions of other tested chemo-
A.
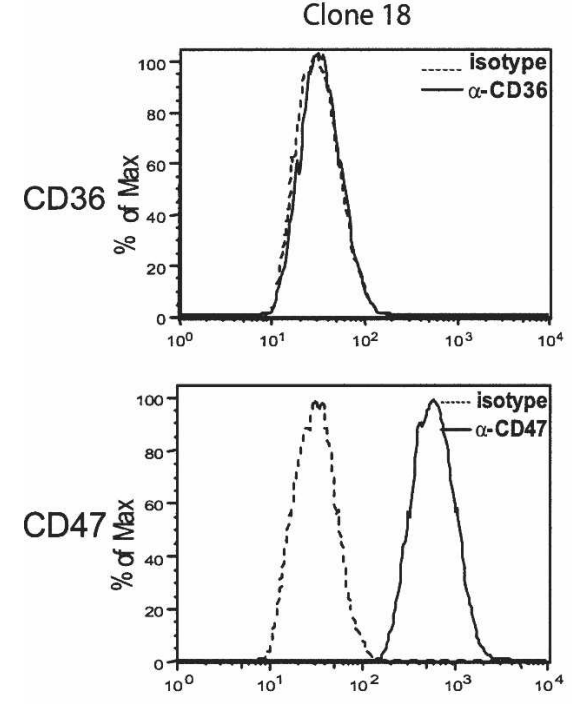

C.

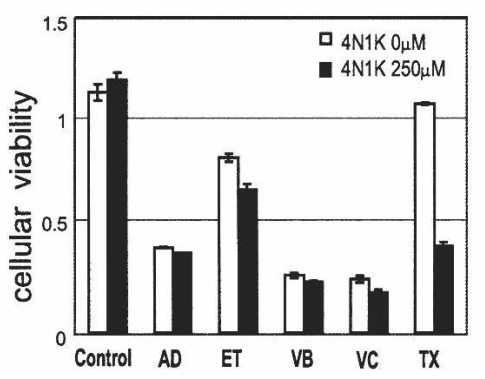

B.
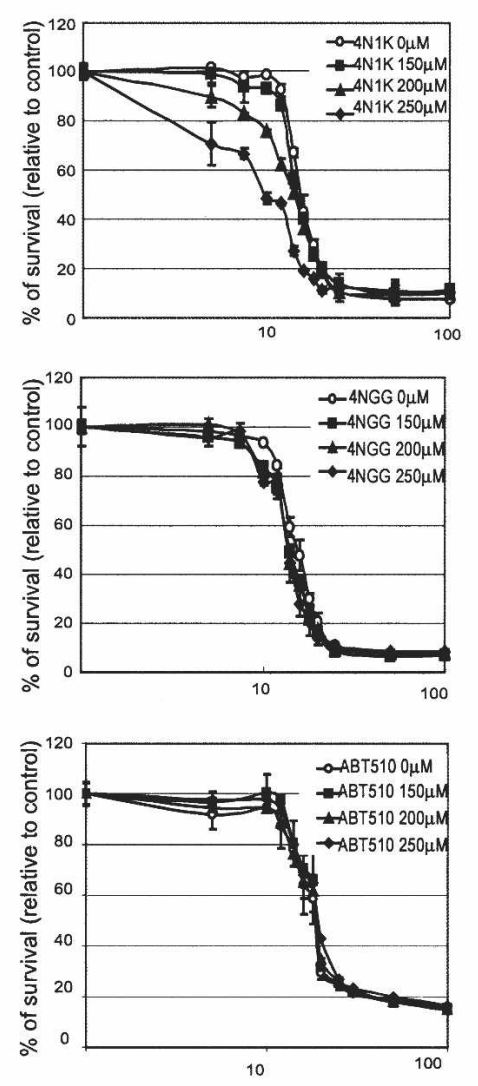

D.
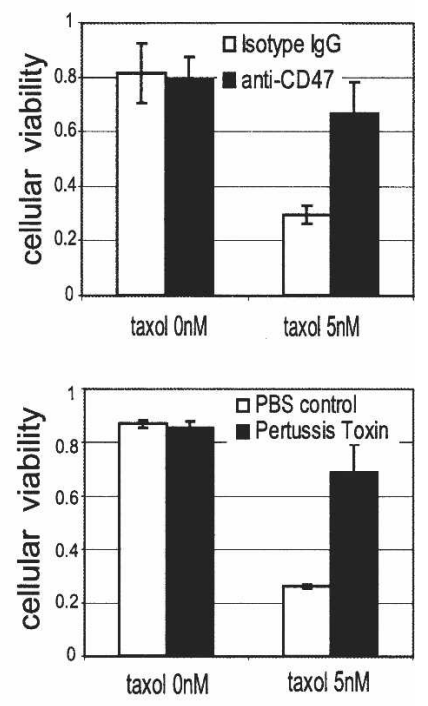

E.

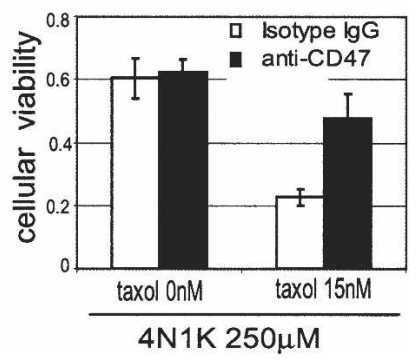

Figure 7. TSP-1 signaling is mediated through CD47. (A) Expression of TSP-1 receptors on clone 18 cells. Clone 18 cells were stained with anti-CD36 antibody (upper panels), anti-CD47 (lower panels), and isotype control immunoglobulin (dotted lines) and analyzed by flow cytometry. The $X$-axis in the histogram is the fluorescence intensity, and the $Y$-axis is the frequency in percentage (maximum number is set as $100 \%$ ). (B) Effect of $4 \mathrm{~N} 1 \mathrm{~K}$ (CD47 agonist peptide) on taxol sensitivity. Cell viability of clone 18 cells treated with the indicated concentrations of TSP-1 mimetic peptides (4N1K, top panel; 4NGG, middle panel; ABT-510, lower panel) was assessed by MTT assay at various concentrations of taxol. Each data point represents the mean \pm SD from four replicates. $(C) 4 \mathrm{~N} 1 \mathrm{~K}$ enhancement of drug sensitivity is specific to taxol. Cell viability of clone 18 cells treated with indicated drugs in the presence or absence of $4 \mathrm{~N} 1 \mathrm{~K}$ was assessed by MTT assay. Abbreviations are the same as in Figure 6C. (D) Effect of anti-CD47 antibody and pertussis toxin on taxol cytotoxicity. Cell viability of M2182tTA cells treated with the indicated concentrations of taxol in the presence of $10 \mu \mathrm{g} / \mathrm{mL}$ anti-CD47 antibody or control isotype IgG (top panel) or $0.5 \mu \mathrm{g} / \mathrm{mL}$ pertussis toxin (lower panel) was assessed by MTT assay. (E) Anti-CD47 antibody abrogates the effect of $4 \mathrm{~N} 1 \mathrm{~K}$ on reversal of taxane resistance in clone 18 . Cell viability of clone 18 cells treated with $250 \mu \mathrm{M} 4 \mathrm{~N} 1 \mathrm{~K}$ in the presence of $10 \mu \mathrm{g} / \mathrm{mL}$ of anti-CD47 antibody or control isotype IgG was accessed by MTT assay at the indicated taxol concentration. 
therapeutic agents. We wished to understand the basis for the observed taxane-related specificity. Earlier work has shown that the anti-angiogenic effects of TSP-1 result from its ability to promote apoptosis of endothelial cells through signaling pathways initiated by its interaction with CD36 receptors on the cell surface (Jimenez et al. 2000). TSP-1 can also regulate cell adhesion and migration through its interaction with a different receptor, CD47, also known as the integrin-associated protein (IAP) (Brown and Frazier 2001). During flow cytometry experiments that investigated expression of each of these receptors in clone 18 (Fig. 7A) and parental M2182tTA cells (Supplemental Fig. S2A), we detected only CD47 at the cell surface-leading us to hypothesize that modulation of taxane resistance by TSP-1 may be mediated through this receptor protein. To determine the correctness of this notion, we examined the ability of the CD47 agonist peptide, $4 \mathrm{~N} 1 \mathrm{~K}$, which corresponds to a sequence (amino acid residues 1016-1023; see peptide sequence in Supplemental Materials and Methods) near the C-terminal end of TSP-1, to affect taxane cytotoxicity; this peptide has been shown to bind highly specifically to CD47 and to have actions similar to those of full-length TSP-1 protein on CD47-mediated signaling of cell migration (Gao et al. 1996a). 4NGG, an inactive variant of 4N1K, and ABT-510, a CD36 agonist peptide (Reiher et al. 2002; Haviv et al. 2005), were used as controls. As seen in Figure $7 \mathrm{~B}$, exposure of clone 18 cells to $4 \mathrm{~N} 1 \mathrm{~K}$ resulted in dose-dependent partial reversal of the taxol resistance induced by overexpression of Txr1 in clone 18 (Fig. 7B, upper panel), whereas the same concentration of peptide 4NGG or ABT-510 had no effect on taxol cytotoxicity (Fig. 7B, middle and lower panels). Similarly, as we observed for the full-length TSP-1 protein, 4N1K, but not 4NGG or ABT-510, enhanced taxol killing of M2182tTA cells growing in culture (Supplemental Fig. S2B), further implicating CD47 in TSP-1 modulation of taxane cytotoxicity. In contrast, the $4 \mathrm{~N} 1 \mathrm{~K}$ peptide did not alter the sensitivity of either clone 18 (Fig. 7C) or M2182tTA cells (Supplemental Fig. S2C) to other chemotherapeutic agents we tested.

The above results indicate that TSP-1-initiation of CD47-mediated signaling is sufficient to enhance the cytotoxicity of taxanes. Experiments we carried out using a monoclonal antibody that specifically interferes with the functioning of CD47 (Blystone et al. 1994; Gao et al. 1996a,b) established that CD47 is also necessary for TSP-1 enhancement of taxane effects. In these studies, anti-CD47 antibody increased the survival of taxoltreated M2182tTA cells in MTT assays by more than twofold (Fig. 7D, upper panel). Increased survival during taxol treatment was observed also in cells exposed to pertussis toxin, which uncouples the heterotrimeric inhibitory G protein, Gi from CD47 (Brown and Frazier 2001), and interrupts CD47-mediated signaling (Fig. 7D, lower panel; Moss and Vaughan 1988). Consistent with these findings, reversal of taxol resistance in clone 18 cancer cells by the $4 \mathrm{~N} 1 \mathrm{~K}$ peptide also depended on the function of CD47, as anti-CD47 antibody abrogated this effect (Fig. 7E). Collectively, these experiments show that the regulation of taxane cytotoxicity by TSP-1 in the cancer cells we have studied occurs by TSP-1 activation of the CD47/integrin-associated protein-signaling pathway.

\section{Discussion}

\section{Novel role of Txr1 in taxane resistance}

The results reported here reveal a previously unknown mechanism that modulates the cellular cytoxicity of taxanes. We show that Txr1, identified earlier by its DNA sequence only as a putative protein of unknown function, is a transcriptional down-regulator of the important proapoptotic, anti-angiogenic protein thrombospondin1, and that Txr1-mediated down-regulation of TSP-1 decreases taxane-induced apoptosis. The causal role of $t \times r 1$ as a modulator of taxane cytotoxicity was demonstrated by the parallel regulation of taxane resistance and Txr1 expression by $\mathrm{Tc}$, by the ability of siRNA directed against $\operatorname{txr} 1$ transcripts to decrease taxol resistance, and by $\mathrm{Tc}$-controlled recapitulation of resistance in naive cells by adventitious expression of the Txr1 protein. The actions of Txr1 on taxane cytotoxicity are independent of the multidrug resistance (MDR) and tubulin-regulated mechanisms of taxane resistance described earlier. Txr1 expression did not affect the cellular accumulation of $\left[{ }^{3} \mathrm{H}\right]$-labeled taxol in clone 18 cells as is observed in MDR (Bradley and Ling 1994), and a MDR inhibitor had no effect on the taxol resistance of these cells. Consistent with these observations, neither was Txr1 expression accompanied by reduced sensitivity to any of several other drugs we tested, including DNA-damaging agents or non-taxane microtubule destabilizing or stabilizing drugs, and clone 18 cells showed no increase in isoforms of microtubules that commonly are up-regulated in tubulin-related mechanisms of taxol resistance. Quantitative biochemical analysis showed the same tubulin dynamics as parental cells.

The function-based screen we used to identify txr1 as a regulator of taxane resistance was designed to discover human genes whose homozygous inactivation by an antisense mechanism results in phenotypes of interest $(\mathrm{Li}$ and Cohen 1996). Subsequent analysis indicated that the predicted transcriptional start site of the $\operatorname{txr} 1$ gene is located $0.5 \mathrm{~kb} 3^{\prime}$ to the site of insertion of the GSV2 retrovirus and that the taxane resistance of the cell clone we isolated resulted from up-regulation, rather than down-regulation, of $\operatorname{txr} 1$ by the GSV2. We speculate that such up-regulation resulted from insertion of the enhancer segment of the GSV2-borne TcRP promoter near the transcription start site of Txr1.

\section{Role of TSP-1 in taxane cytotoxicity}

Our investigations showed that the abundances of $\operatorname{txr} 1$ and TSP-1 at both mRNA and protein levels were reciprocally related in a wide variety of cancer cell lines, that increase in $\operatorname{txr} 1$ and decrease in TSP-1 expression was 
highly correlated with taxane resistance in these cancer cells, and that Txr1 down-regulates transcription from the TSP-1 promoter. Multiple types of additional evidence confirmed the role of TSP-1 as both a target of Txr1 regulation and a mediator of cellular resistance to taxanes, and defined the mechanism for this effect: (1) Down-regulation of TSP-1 expression by siRNA resulted in increased taxane resistance; (2) taxane resistance induced by elevation of Txr1 was reversed by addition of purified TSP-1 protein or the TSP-1 mimetic peptide $4 \mathrm{~N} 1 \mathrm{~K}$ to cell cultures; and (3) interference with TSP-1mediated signaling by antibody directed against the CD47 receptor resulted in cellular resistance to taxanes and also abrogated the ability of $4 \mathrm{~N} 1 \mathrm{~K}$ to enhance taxane-induced cell death. The structural features of Txr1, which lacks domains commonly seen in DNA-binding proteins, suggest that regulation of TSP-1 expression by Txr1 may occur by an interaction with other members of the multicomponent complex that modulates transcription of the TSP-1 gene (Volpert and Alani 2003), rather than by direct interaction of Txr1 with the TSP-1 promoter.

The abundance of multiple other cellular transcripts was also altered by Txr1 (Fig. 5A), and we do not exclude the possibility that Txrl may additionally affect taxane lethality through a TSP-1-independent mechanism. For example, elevated expression of the mitogen-activated protein kinase kinase kinase-1 (MAP3K1, or MEKK1), which we found was induced by Txr1 (Supplemental Table 1), has been reported to protect cells from taxolinduced apoptosis (Yujiri et al. 1999). Additionally, inhibition of cyclin-dependent kinases (CDKs) can decrease the lethality of taxol (Schmidt et al. 2001), and we observed that transcripts of the CDK-binding protein cyclin D2 were reduced in cells overexpressing Txr1. It has not been determined whether these Txr1-induced perturbations supplement the effects we have observed on taxane cytotoxicity mediated by the Txr1/TSP-1 pathway.

\section{Signaling of Txr1-induced TSP-1-mediated taxane resistance through the CD47/ \\ integrin-associated protein}

The anti-angiogenic effects of TSP-1 result from its interaction with the CD36 receptor protein, which is expressed on the surface of endothelial cells (Jimenez et al. 2000; Volpert et al. 2002b), and these effects are mimicked by the ABT-510 peptide, which interacts specifically with this receptor (Reiher et al. 2002; Haviv et al. 2005). The CD36-binding ABT-510 peptide has been shown to enhance the ability of adriamycin and certain other chemotherapeutic drugs to kill endothelial cells that express CD36 (Quesada et al. 2005; Yap et al. 2005).

The ability of the Txr1/TSP-1 pathway to modulate taxane cytotoxicity in M2182 prostate cancer cells growing in culture, rather than as xenografts, allows us to conclude that this pathway's effects on tumor cell survival are direct, instead of being mediated through angiogenesis. Moreover, we found that enhancement of taxane-induced apoptosis by the addition of TSP-1 pro- tein or the TSP-1 mimetic peptide $4 \mathrm{~N} 1 \mathrm{~K}$ to cancer cell cultures is mediated through a distinct cell surface receptor (i.e., CD47) that previously has been implicated in the effects of TSP-1 and 4N1K on platelet activation, cell migration and adhesion, phagocytosis (Brown and Frazier 2001), and T-cell activation (Waclavicek et al. 1997; Li et al. 2001). Specific involvement of CD47 in Txr1-induced TSP-1-mediated taxol lethality in M2182 prostate cancer cells was shown by the ability of the CD47-specific $4 \mathrm{~N} 1 \mathrm{~K}$ peptide to recapitulate TSP-1 effects in these cells, the ability of anti-CD47 antibody to mitigate the effects of the 4N1K peptide on taxol sensitivity, and the ability of pertussis toxin-which interferes with Gi-dependent CD47-mediated cell death (Manna and Frazier 2004) — to alter taxane lethality.

The lack of any detectable effect of the ABT-510 peptide on taxane sensitivity of M2182tTA or clone 18 cells is consistent with the absence of CD36 expression on the surface of these cells. However, adventitious expression of CD36 in M2182tTA did not sensitize these prostate cancer cells to either the proapoptotic effects of ABT-510 or to adriamycin (C.-J. Lih and S.N. Cohen, unpubl.), indicating that CD36-mediated signaling by TSP1 may require still additional genetic functions that are absent in the tumor cells we have studied. Whereas the investigations we have reported here were not intended to elucidate the clinical role of the Txr1/TSP-1 pathway in the effects of taxanes on chemotherapeutically related cancers, our results do show a high correlation between taxane resistance and expression levels of Txr1 and TSP-1 in 13 of 19 NCI-60 cell lines derived from multiple types of human cancers. These findings suggest that direct clinical study of Txr1/TSP-1-mediated signaling in taxane-treated tumors may be warranted.

\section{Materials and methods}

\section{Plasmids}

The gene search vector (GSV2) used to identify txr1 (Fig. 1A) was modified from a previously described retroviral vector ( $\mathrm{Li}$ and Cohen 1996). The pEGFPTxr1 plasmid was constructed by inserting a txr 1 cDNA fragment into the BglII and EcoRI sites of pCMV-EGFPN1 (BD Biosciences Clontech). pLEST-Txr1HA was constructed by inserting a txr1 cDNA fragment tagged with a $3^{\prime}$ HA-encoding sequence into the NheI site of lentivirusbased vector pLEST (Lu et al. 2004). A TSP-1 promoter-controlled luciferase reporter construct, pTSP1.7Luc, was a gift from Dr. Susan Cohn (Department of Pediatrics, Northwestern University) (Yang et al. 2003).

\section{Construction of GSV2 mutated library and selection} of taxol-resistant cells

M2182 cells and derivatives were cultured as described (Bae et al. 1998). M2182tTA cells established by introducing a construct expressing the Tc-repressed transactivator (tTA) were infected by GSV2 retrovirus, which was produced as described (Ory et al. 1996). For selection of taxol resistance cell clones, a pool of cells containing $5 \times 10^{5}$ independent GSV2 virus permanent insertions was seeded at $5 \times 10^{5}$ per 10 -cm plate for a 2 -wk treatment of $10 \mathrm{nM}$ taxol. Surviving colonies were pooled and 
exposed to $10 \mathrm{nM}$ taxol in a second round of screening for taxolresistant colonies.

\section{Cell viability assay}

For plate assays, $1 \times 10^{4}$ cells per 10 -cm plate or per each well of a six-well plate were seeded $1 \mathrm{~d}$ prior to 5-7 d of drug treatment. Resistant colonies were fixed and stained with $0.5 \%$ crystal violet solution (in 70\% ethanol) and photographed. For quantitative determination of the surviving fraction, the crystal violetstained colonies were extracted using $0.5 \mathrm{~mL}$ of $100 \%$ DMSO solution overnight, and the absorbance of the solution at 570 $\mathrm{nm}$ was measured. The fraction of surviving cells was calculated relative to untreated controls. Results were averaged from at least two independent experiments. For $\mathrm{IC}_{50}$ determination, $3 \times 10^{3}$ cells per well of a 96-well plate were seeded $1 \mathrm{~d}$ prior to treatment by serially diluted drugs or indicated protein/peptides. Cell viability was quantified by ability to reduce tetrazolium salt 3-(4,5-dimethylthiazol-2-y)-2,5-diphenyl tetrasodium bromide (MTT; Sigma) to a formazan dye whose absorbance is detectable at $570 \mathrm{~nm}$. The $\mathrm{IC}_{50}$ value was defined as the dose of drug that inhibited cell growth by $50 \%$. For TUNEL assays, $5 \times 10^{4}$ cells/well were seeded on circular coverslips in 24-well plates $1 \mathrm{~d}$ prior to treatment with chemotherapeutic drug for $3 \mathrm{~d}$ in the presence or absence of $7.5 \mu \mathrm{g} / \mathrm{mL}$ purified TSP-1. Cells fixed with $4 \%$ paraformaldehyde for 10 min were permeabilized with $0.3 \%$ Triton X-100 for 5 min and incubated with TdT reaction buffer (Roche Molecular Biochemicals) at $37^{\circ} \mathrm{C}$ for $2 \mathrm{~h}$. Images were acquired by using a confocal microscope (Leica).

Cloning of provirus integration site by PCR-based genomic walking

Genomic DNA was extracted from taxol-resistant cells by using the Gentra genomic DNA extraction kit (Gentra Systems). Genomic DNA 3' to the GSV2 integration site was cloned using the GenomeWalker kit (BD Biosciences, Clontech) followed by PCR amplification using Expand High Fidelity PCR Systems (Roche Applied Science). An oligonucleotide corresponding in sequence to the sense strand of the neo gene $\left(5^{\prime}\right.$-GCTGACCGCTTCCTCGTGCTTTACGG-3') indicated as a broken arrow in Figure 1 was used as primer.

\section{siRNA-mediated knockdown of gene expression}

Two siRNA duplexes corresponding to segments of txr1 mRNA (accession number AF217517), SI1 (80-102, 5'-AAGAGCGAGACUGCGAAGGAGAdTdT-3' and 5'-UCUCCUUCGCAGUCUCGGCUCdTdT-3') and SI2 (761-783, 5' -AAGAGGAUUGCCAUGGCCUGGCCdTdT- $3^{\prime}$ and $5^{\prime}$-GGCCAGGCCAUGGCAAUCCUCdTdT-3'), and a presynthesized scrambled sequence control (nonspecific Control Duplex VIII) were purchased from Dharmacon. An siRNA duplex directed against TSP-1 transcripts was purchased from Santa Cruz Biotechnology (SC \#29528). Cells $\left(2 \times 10^{5}\right)$ were plated in six-well dishes 1 $\mathrm{d}$ prior to transfection of cells with $50 \mathrm{nM}$ siRNA oligonucleotides using DharmaFECT (Dharmacon). Twenty-four hours later, transfected cells were analyzed for taxol resistance by colony formation assay or MTT assay.

\section{Immunoblotting and immunofluorescence}

A peptide, N15 (AGQPGPNPYPPNIGC, amino acids 6-20) (Fig. $2 \mathrm{~B})$, corresponding to a segment of Txr1 was synthesized and used as antigen for raising rabbit polyclonal antibodies by Co- vance. Immunoblots were probed with anti- $\alpha$-tubulin monoclonal antibody (1:5000; Sigma), anti-Txr1 antibody (1:1000 dilution), and anti-TSP-1 (1:250; Lab Vision), and chemiluminescence signals were quantitatively traced by the VersaDoc imaging system (Bio-Rad). Immunofluorescence staining was carried out as described previously (Xie et al. 1998). Briefly, cells were fixed, permeabilized, blocked, and incubated with either anti-Txr1 antibody or pre-immune serum (1:250 dilution), and then with secondary antibody conjugated with Oregon Green 488 (1:500 dilution; Invitrogen). Cells transfected with GFPTxr1 fusion constructs were fixed with $4 \%$ paraformaldehyde for $10 \mathrm{~min}$ and stained with DAPI for $10 \mathrm{~min}$. Fluorescent images were obtained by confocal microscopy.

\section{cDNA microarray and NCI-60 data analysis}

Manufacture of cDNA microarrays containing $\sim 42,000$ sequence-verified IMAGE clones ( 28,000 different genes), the labeling of fluorescent cDNA, and hybridization methods were as described (http://cmgm.stanford.edu/pbrown/protocols/ index.html). Data were processed and analyzed by GABRIEL as described previously (Pan et al. 2002; Zhang et al. 2003). Briefly, a pattern-based algorithm that selects genes showing reduced or elevated expression in clone 18 by Tc, but no changed expression in M2182tTA by Tc, was used. "Elevated" or "reduced" expression was defined by thresholds that yielded false discovery rate (FDR) values $<0.001$. For NCI-60 data analysis, drug activity data (A-matrix) were downloaded from http:// discover.nci.nih.gov/datasetsNature2000.jsp, and gene expression data were downloaded from http://genome-www5.stanford. edu/cgi-bin/publication/viewPublication.pl?pub_no=81. Application of a data quality filter identified 19 cell lines having analyzable data for gene expression of both Txr1 (gene name DKFZP51J157) and TSP-1 (THBS). The Pearson correlation coefficient of taxol sensitivity with expression of Txr1 and TSP-1 was determined by the mean center method as described in Pan et al. (2002) for 13 of these 19 lines that showed reciprocally altered expression of Txr1 and TSP-1.

Additional materials and methods information is available in the Supplemental Materials and Methods.

\section{Acknowledgments}

We thank Yuchin Teng for excellent assistance in virus preparation and cell culture. We thank Dr. Susan Cohn for the gift of TSP-1 promoter luciferase constructs and Abbott Laboratories for the ABT-510 peptide. Our research was supported in part by grants from the California Cancer Research Program, the California Breast Cancer Research Program, and the National Foundation for Cancer Research awarded to C.-J.L. and/or S.N.C., and also by other research funds awarded to S.N.C.

\section{References}

Bae, V.L., Jackson-Cook, C.K., Maygarden, S.J., Plymate, S.R., Chen, J., and Ware, J.L. 1998. Metastatic sublines of an SV40 large $\mathrm{T}$ antigen immortalized human prostate epithelial cell line. Prostate 34: 275-282.

Berns, K., Hijmans, E.M., Mullenders, J., Brummelkamp, T.R., Velds, A., Heimerikx, M., Kerkhoven, R.M., Madiredjo, M., Nijkamp, W., Weigelt, B., et al. 2004. A large-scale RNAi screen in human cells identifies new components of the p53 pathway. Nature 428: 431-437.

Blystone, S.D., Graham, I.L., Lindberg, F.P., and Brown, E.J. 1994. Integrin $\alpha_{v} \beta_{3}$ differentially regulates adhesive and 
Lih et al.

phagocytic functions of the fibronectin receptor $\alpha_{5} \beta_{1}$. J. Cell Biol. 127: 1129-1137.

Bradley, G. and Ling, V. 1994. P-Glycoprotein, multidrug resistance and tumor progression. Cancer Metastasis Rev. 13: 223-233.

Brown, E.J. and Frazier, W.A. 2001. Integrin-associated protein (CD47) and its ligands. Trends Cell Biol. 11: 130-135.

Cheung, H.W., Ling, M.T., Tsao, S.W., Wong, Y.C., and Wang, X. 2004. Id-1-induced Raf/MEK pathway activation is essential for its protective role against taxol-induced apoptosis in nasopharyngeal carcinoma cells. Carcinogenesis 25: 881887.

Damber, J.E., Vallbo, C., Albertsson, P., Lennernas, B., and Norrby, K. 2006. The anti-tumour effect of low-dose continuous chemotherapy may partly be mediated by thrombospondin. Cancer Chemother. Pharmacol. 58: 354-360.

de Fraipont, F., Nicholson, A.C., Feige, J.J., and Van Meir, E.G. 2001. Thrombospondins and tumor angiogenesis. Trends Mol. Med. 7: 401-407.

Gao, A.G., Lindberg, F.P., Dimitry, J.M., Brown, E.J., and Frazier, W.A. 1996a. Thrombospondin modulates $\alpha_{\mathrm{v}} \beta_{3}$ function through integrin-associated protein. J. Cell Biol. 135: 533544.

Gao, A.G., Lindberg, F.P., Finn, M.B., Blystone, S.D., Brown, E.J., and Frazier, W.A. 1996b. Integrin-associated protein is a receptor for the C-terminal domain of thrombospondin. I. Biol. Chem. 271: 21-24.

Giannakakou, P., Sackett, D.L., Kang, Y.K., Zhan, Z., Buters, J.T., Fojo, T., and Poruchynsky, M.S. 1997. Paclitaxel-resistant human ovarian cancer cells have mutant $\beta$-tubulins that exhibit impaired paclitaxel-driven polymerization. $J$. Biol. Chem. 272: 17118-17125.

Harada, H., Nakagawa, K., Saito, M., Kohno, S., Nagato, S., Furukawa, K., Kumon, Y., Hamada, K., and Ohnishi, T. 2003. Introduction of wild-type p53 enhances thrombospondin-1 expression in human glioma cells. Cancer Lett. 191: 109119.

Haviv, F., Bradley, M.F., Kalvin, D.M., Schneider, A.J., Davidson, D.J., Majest, S.M., McKay, L.M., Haskell, C.J., Bell, R.L., Nguyen, B., et al. 2005. Thrombospondin-1 mimetic peptide inhibitors of angiogenesis and tumor growth: Design, synthesis, and optimization of pharmacokinetics and biological activities. J. Med. Chem. 48: 2838-2846.

Horwitz, S.B. 1992. Mechanism of action of taxol. Trends Pharmacol. Sci. 13: 134-136.

Horwitz, S.B., Cohen, D., Rao, S., Ringel, I., Shen, H.J., and Yang, C.P. 1993. Taxol: Mechanisms of action and resistance. J. Natl. Cancer Inst. Monogr. (15) 55-61.

Jimenez, B., Volpert, O.V., Crawford, S.E., Febbraio, M., Silverstein, R.L., and Bouck, N. 2000. Signals leading to apoptosisdependent inhibition of neovascularization by thrombospondin-1. Nat. Med. 6: 41-48.

Kavallaris, M., Kuo, D.Y., Burkhart, C.A., Regl, D.L., Norris, M.D., Haber, M., and Horwitz, S.B. 1997. Taxol-resistant epithelial ovarian tumors are associated with altered expression of specific $\beta$-tubulin isotypes. J. Clin. Invest. 100: 12821293.

Kimchi, A. 2003. Antisense libraries to isolate tumor suppressor genes. Methods Mol. Biol. 222: 399-412.

Li, L. and Cohen, S.N. 1996. Tsg101: A novel tumor susceptibility gene isolated by controlled homozygous functional knockout of allelic loci in mammalian cells. Cell 85: 319329.

Li, Z., He, L., Wilson, K., and Roberts, D. 2001. Thrombospondin-1 inhibits TCR-mediated T lymphocyte early activation. J. Immunol. 166: 2427-2436.
Li, K., Yang, M., Yuen, P.M., Chik, K.W., Li, C.K., Shing, M.M., Lam, H.K., and Fok, T.F. 2003. Thrombospondin-1 induces apoptosis in primary leukemia and cell lines mediated by CD36 and Caspase-3. Int. J. Mol. Med. 12: 995-1001.

Lu, Q., Wei, W., Kowalski, P.E., Chang, A.C., and Cohen, S.N. 2004. EST-based genome-wide gene inactivation identifies ARAP3 as a host protein affecting cellular susceptibility to anthrax toxin. Proc. Natl. Acad. Sci. 101: 17246-17251.

Manna, P.P. and Frazier, W.A. 2004. CD47 mediates killing of breast tumor cells via Gi-dependent inhibition of protein kinase A. Cancer Res. 64: 1026-1036.

Monzo, M., Rosell, R., Sanchez, J.J., Lee, J.S., O'Brate, A., Gonzalez-Larriba, J.L., Alberola, V., Lorenzo, J.C., Nunez, L., Ro, J.Y., et al. 1999. Paclitaxel resistance in non-small-cell lung cancer associated with $\beta$-tubulin gene mutations. $J$. Clin. Oncol. 17: 1786-1793.

Moss, J. and Vaughan, M. 1988. ADP-ribosylation of guanyl nucleotide-binding regulatory proteins by bacterial toxins. Adv. Enzymol. Relat. Areas Mol. Biol. 61: 303-379.

Ory, D.S., Neugeboren, B.A., and Mulligan, R.C. 1996. A stable human-derived packaging cell line for production of high titer retrovirus/vesicular stomatitis virus G pseudotypes. Proc. Natl. Acad. Sci. 93: 11400-11406.

Pan, K.H., Lih, C.J., and Cohen, S.N. 2002. Analysis of DNA microarrays using algorithms that employ rule-based expert knowledge. Proc. Nat1. Acad. Sci. 99: 2118-2123.

Parekh, H. and Simpkins, H. 1996. Species-specific differences in taxol transport and cytotoxicity against human and rodent tumor cells. Evidence for an alternate transport system. Biochem. Pharmacol. 51: 301-311.

Primiano, T., Baig, M., Maliyekkel, A., Chang, B.D., Fellars, S., Sadhu, J., Axenovich, S.A., Holzmayer, T.A., and Roninson, I.B. 2003. Identification of potential anticancer drug targets through the selection of growth-inhibitory genetic suppressor elements. Cancer Cell 4: 41-53.

Quesada, A.J., Nelius, T., Yap, R., Zaichuk, T.A., Alfranca, A., Filleur, S., Volpert, O.V., and Redondo, J.M. 2005. In vivo upregulation of CD95 and CD95L causes synergistic inhibition of angiogenesis by TSP1 peptide and metronomic doxorubicin treatment. Cell Death Differ. 12: 649-658.

Ranganathan, S., Benetatos, C.A., Colarusso, P.J., Dexter, D.W., and Hudes, G.R. 1998. Altered $\beta$-tubulin isotype expression in paclitaxel-resistant human prostate carcinoma cells. Br. J. Cancer 77: 562-566.

Reiher, F.K., Volpert, O.V., Jimenez, B., Crawford, S.E., Dinney, C.P., Henkin, J., Haviv, F., Bouck, N.P., and Campbell, S.C. 2002. Inhibition of tumor growth by systemic treatment with thrombospondin-1 peptide mimetics. Int. J. Cancer 98: 682-689.

Rowinsky, E.K. 1997. Paclitaxel pharmacology and other tumor types. Semin. Oncol. 24: S19-1-S19-12.

Sargiannidou, I., Zhou, J., and Tuszynski, G.P. 2001. The role of thrombospondin-1 in tumor progression. Exp. Biol. Med. (Maywood) 226: 726-733.

Scherf, U., Ross, D.T., Waltham, M., Smith, L.H., Lee, J.K., Tanabe, L., Kohn, K.W., Reinhold, W.C., Myers, T.G., Andrews, D.T., et al. 2000. A gene expression database for the molecular pharmacology of cancer. Nat. Genet. 24: 236-244.

Schmidt, M., Lu, Y., Parant, J.M., Lozano, G., Bacher, G., Beckers, T., and Fan, Z. 2001. Differential roles of p21Waf1 and p27Kip1 in modulating chemosensitivity and their possible application in drug discovery studies. Mol. Pharmacol. 60: 900-906.

Sid, B., Sartelet, H., Bellon, G., El Btaouri, H., Rath, G., Delorme, N., Haye, B., and Martiny, L. 2004. Thrombospondin 1: A multifunctional protein implicated in the regulation of 
tumor growth. Crit. Rev. Oncol. Hematol. 49: 245-258.

Volpert, O.V. and Alani, R.M. 2003. Wiring the angiogenic switch: Ras, Myc, and Thrombospondin-1. Cancer Cell 3: 199-200.

Volpert, O.V., Pili, R., Sikder, H.A., Nelius, T., Zaichuk, T., Morris, C., Shiflett, C.B., Devlin, M.K., Conant, K., and Alani, R.M. 2002a. Id1 regulates angiogenesis through transcriptional repression of thrombospondin-1. Cancer Cell 2: 473-483.

Volpert, O.V., Zaichuk, T., Zhou, W., Reiher, F., Ferguson, T.A., Stuart, P.M., Amin, M., and Bouck, N.P. 2002b. Inducerstimulated Fas targets activated endothelium for destruction by anti-angiogenic thrombospondin- 1 and pigment epithelium-derived factor. Nat. Med. 8: 349-357.

Waclavicek, M., Majdic, O., Stulnig, T., Berger, M., Baumruker, T., Knapp, W., and Pickl, W.F. 1997. T cell stimulation via CD47: Agonistic and antagonistic effects of CD47 monoclonal antibody 1/1A4. J. Immunol. 159: 5345-5354.

Wahl, A.F., Donaldson, K.L., Fairchild, C., Lee, F.Y., Foster, S.A., Demers, G.W., and Galloway, D.A. 1996. Loss of normal p53 function confers sensitization to Taxol by increasing $\mathrm{G}_{2} / \mathrm{M}$ arrest and apoptosis. Nat. Med. 2: 72-79.

Xie, W., Li, L., and Cohen, S.N. 1998. Cell cycle-dependent subcellular localization of the TSG101 protein and mitotic and nuclear abnormalities associated with TSG101 deficiency. Proc. Natl. Acad. Sci. 95: 1595-1600.

Xu, X., Leo, C., Jang, Y., Chan, E., Padilla, D., Huang, B.C., Lin, T., Gururaja, T., Hitoshi, Y., Lorens, J.B., et al. 2001. Dominant effector genetics in mammalian cells. Nat. Genet. 27: 23-29.

Yang, Q.W., Liu, S., Tian, Y., Salwen, H.R., Chlenski, A., Weinstein, J., and Cohn, S.L. 2003. Methylation-associated silencing of the thrombospondin-1 gene in human neuroblastoma. Cancer Res. 63: 6299-6310.

Yap, R., Veliceasa, D., Emmenegger, U., Kerbel, R.S., McKay, L.M., Henkin, J., and Volpert, O.V. 2005. Metronomic lowdose chemotherapy boosts CD95-dependent anti-angiogenic effect of the thrombospondin peptide ABT-510: A complementation anti-angiogenic strategy. Clin. Cancer Res. 11: 6678-6685.

Yoo, G.H., Piechocki, M.P., Ensley, J.F., Nguyen, T., Oliver, J., Meng, H., Kewson, D., Shibuya, T.Y., Lonardo, F., and Tainsky, M.A. 2002. Docetaxel induced gene expression patterns in head and neck squamous cell carcinoma using cDNA microarray and PowerBlot. Clin. Cancer Res. 8: 3910-3921.

Yoo, G.H., Lin, H.S., Iskander, A.J., Piechocki, M.P., Oliver, J., Kewson, D., Lonardo, F., Tainsky, M.A., Kim, H.R., Kim, H., et al. 2005. Docetaxel associated pathways in cisplatin resistant head and neck squamous cell carcinoma: A pilot study. Laryngoscope 115: 1938-1946.

Yujiri, T., Fanger, G.R., Garrington, T.P., Schlesinger, T.K., Gibson, S., and Johnson, G.L. 1999. MEK kinase 1 (MEKK1) transduces c-Jun NH2-terminal kinase activation in response to changes in the microtubule cytoskeleton. J. Biol. Chem. 274: 12605-12610.

Zhang, H., Pan, K.H., and Cohen, S.N. 2003. Senescence-specific gene expression fingerprints reveal cell-type-dependent physical clustering of up-regulated chromosomal loci. Proc. Natl. Acad. Sci. 100: 3251-3256. 


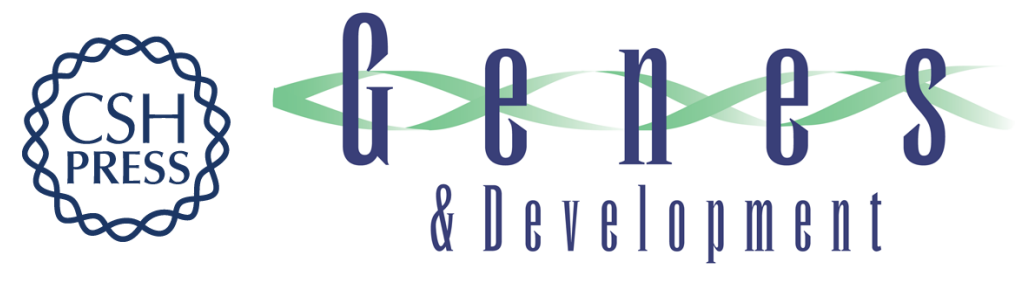

\section{Txr1: a transcriptional regulator of thrombospondin-1 that modulates cellular sensitivity to taxanes}

Chih-Jian Lih, Wensheng Wei and Stanley N. Cohen

Genes Dev. 2006, 20:

Access the most recent version at doi:10.1101/gad.1441306

\section{Supplemental http://genesdev.cshlp.org/content/suppl/2006/07/14/gad.1441306.DC1 \\ Material}

Related Content

TXR1-mediated thrombospondin repression: a novel mechanism of resistance to taxanes?

Renée van Amerongen and Anton Berns

Genes Dev. UNKNOWN , 2006 20: 1975-1981

References This article cites 50 articles, 18 of which can be accessed free at: http://genesdev.cshlp.org/content/20/15/2082.full.html\#ref-list-1

Articles cited in:

http://genesdev.cshlp.org/content/20/15/2082.full.html\#related-urls

\section{License}

Email Alerting

Service

Receive free email alerts when new articles cite this article - sign up in the box at the top right corner of the article or click here.

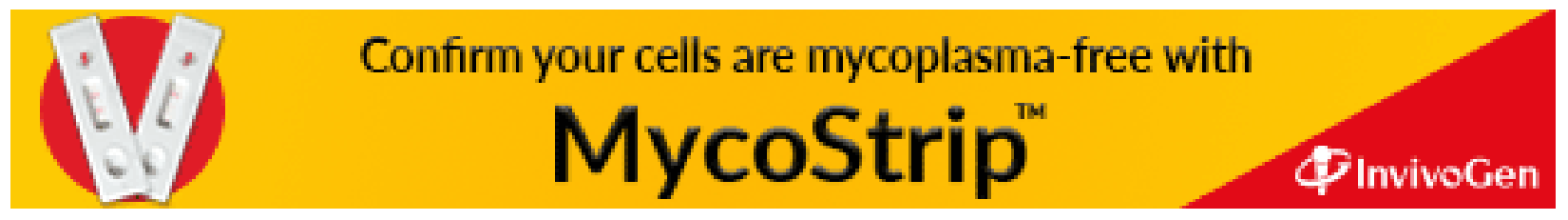

